\title{
Lipoprotein(a) in the Evaluation of Cardiovascular Risk in the Portuguese Population
}

\section{Lipoproteína(a) na Avaliação do Risco Cardiovascular na População Portuguesa}

\author{
Joaquim A. MEIRELES-BRANDÃO四1,2, Lúcia R. MEIRELES-BRANDÃO², Rui COELHO1, \\ Francisco R. ROCHA-GONÇALVES1 \\ Acta Med Port 2019 Mar;32(3):202-207 - https://doi.org/10.20344/amp.10251
}

\section{ABSTRACT}

Introduction: High values of lipoprotein(a), related to atherosclerosis progression, are often considered a marker of thrombosis. We assessed the lipoprotein(a) profile in a group of patients with high vascular risk and no cardiovascular events, established its correlation with other cardiovascular risk factors and inferred the results for patients with metabolic disorders and, at least, two risk factors.

Material and Methods: This longitudinal observational study included 516 patients, who had at least two cardiovascular risk factors and regularly attended, for at least two years, the outpatient consultations at a clinic of metabolism and vascular risk for primary prevention. Sociodemographic, clinical and anthropometric parameters were obtained at the baseline visit. Hepatic morphology was assessed in 509 patients $(98.6 \%)$ by ultrasonography. The 10 -year vascular risk was estimated using Framingham risk score, atherosclerotic cardiovascular disease and systematic coronary risk evaluation tables.

Results: Significant correlations were found between lipoprotein(a) levels and the addressed vascular risk factors, as well as between lipoprotein(a), and Framingham risk score, atherosclerotic cardiovascular disease and systematic coronary risk evaluation charts. Lipoprotein(a) values were also considerably higher in patients with steatosis.

Discussion: Increased lipoprotein(a) values were directly associated with all markers of cardiovascular risk and with non-alcoholic hepatic steatosis.

Conclusion: Due to its high availability and low cost, lipoprotein(a) should become part of the routine evaluation of patients at vascular risk.

Keywords: Atherosclerosis; Cardiovascular Diseases; Lipoprotein(a); Portugal; Primary Prevention

\section{RESUMO}

Introdução: Valores elevados de lipoproteína(a), relacionados com a progressão da aterosclerose, são frequentemente considerados marcadores de trombose. O perfil de lipoproteína(a) foi avaliado num grupo de doentes sem eventos cardiovasculares mas com elevado risco vascular, estabelecendo-se a correlação com outros fatores de risco cardiovascular e inferindo-se os resultados para doentes com alterações metabólicas e, pelo menos, dois fatores de risco vascular.

Material e Métodos: Este estudo observacional longitudinal incluiu 516 doentes com, pelo menos, dois fatores de risco cardiovascular e que frequentavam, regularmente e há pelo menos dois anos, a consulta ambulatória de metabolismo e risco vascular para prevenção primária. Os parâmetros sociodemográficos, clínicos e antropométricos foram recolhidos na primeira visita. A morfologia hepática foi avaliada por ultrassonografia em 509 doentes $(98,6 \%)$. O risco vascular a 10 anos foi estimado através de tabelas de cálculo de risco de Framingham, doença cardiovascular e risco coronário sistemático.

Resultados: Foram encontradas correlações significativas entre os níveis de lipoproteína(a) e os fatores de risco vasculares analisados, assim como entre lipoproteína(a) e as escalas de risco de Framingham, doença cardiovascular e risco coronário sistemático. Os valores de lipoproteína(a) apresentaram-se mais elevados em doentes com esteatose.

Discussão: Os valores elevados de lipoproteína(a) estão diretamente associados com todos os marcadores de risco cardiovascular e com esteatose hepática não alcoólica.

Conclusão: Como tal, considerando a sua elevada acessibilidade e custo reduzido, o marcador lipoproteína(a) deverá ser integrado na avaliação de rotina de doentes com risco vascular.

Palavras-chave: Aterosclerose; Doenças Cardiovasculares; Lipoproteína(a); Portugal; Prevenção Primária

\section{INTRODUCTION}

Atherosclerosis remains the major cause of death and premature disability in developed societies. ${ }^{1}$ Current predictions estimate that by 2020 cardiovascular diseases (CVD), ${ }^{2}$ particularly atherosclerosis, will become a global leading cause of death. ${ }^{3}$ Lipoprotein(a), or $L p(a)$, is identical to the low-density lipoprotein cholesterol (LDLc), with the addition of apolipoprotein A (apoA), a highly glycosylated protein. ${ }^{4,5} \mathrm{Lp}(\mathrm{a})$ is often considered a marker of thrombosis, similarly to plasminogen, and a risk factor for CVD. ${ }^{6}$ The cholesterol present in LDLc accounts for more than half of plasma cholesterol, in most individuals. Approximately $70 \%$ of the circulating LDLc is cleared by LDL-receptor-mediated endocytosis in the liver. ApoA is synthesized in the liver and attached by disulphide linkage to apoB-100, a structural protein of $L p(a)$. Also, apoB is the main structural protein of chylomicrons. ${ }^{2}$ The human liver produces apoB-100, whereas the intestine produces apoB-48. Clearance of Lp(a) occurs mainly through the liver, but the uptake pathway is still unknown. ${ }^{7}$ Nevertheless, Lp(a) is recognized as a strong risk factor for aortic and mitral stenosis in peripheral artery

1. Faculty of Medicine. University of Porto. Porto. Portugal.

2. Starmedica Clinica. Paredes. Portugal.

$\triangle$ Autor correspondente: Joaquim A. Meireles-Brandão. dr.meirelesbrandao@gmail.com

Recebido: 16 de janeiro de 2018 - Aceite: 08 de novembro de 2018 | Copyright @ Ordem dos Médicos 2019 
disease and might present other functions, including an important role in the association between atherosclerosis and thrombosis. 8,9

Portugal is a Southern European country where CVD are the first cause of mortality and stroke incidence is higher compared to other European countries. ${ }^{10}$ In this context, we assessed the levels of $L p(a)$ in Portuguese patients, who regularly attended outpatient consultations at the clinic of metabolism and vascular risk, over a two-year period. In addition, those patients had metabolic disorders and, at least, two cardiovascular risk factors (CVRF), but no previous cardiovascular events. Thus, the aim of this study is to determine the mean values of $L p(a)$ in the sample of patients and to infer the use of $L p(a)$ as an indicator of vascular risk in the Portuguese population with metabolic disorders and, at least, two CVRF.

\section{MATERIAL AND METHODS}

The longitudinal observational study included 516 patients, as a random sample of a universe of 1677 patients from an outpatient setting at a clinic of metabolism and vascular risk. Inclusion criteria were defined for those patients without cardiovascular events having, at least, two family or personal CVRF and attending an outpatient consultation about metabolism and vascular risk for primary prevention, for at least two years (between 1995 and 2015), on a quarterly periodicity. All patients accepted and signed the informed consent form. The protocol used in this study was approved by the local Ethics Committee of the São João Hospital Center. All procedures conducted in this study comply with the Declaration of Helsinki.

Patients were assessed for sociodemographic data, including their professional status, in accordance with the 2010 classification, by the Portuguese National Statistics Institute (Instituto Nacional de Estatística, INE). Afterwards, clinical characterization of the study participants was determined, at baseline, by anthropometric, biochemical and cardiovascular evaluation. The following tests were conducted: electrocardiogram (ECG), two-dimensional echocardiogram with ejection fraction calculation, and doppler ultrasonography of the supra-aortic trunks with evaluation of the carotid intima-media thickness (IMT). In addition, liver morphological changes were evaluated by ultrasonography. For classification of alcohol consumption, the following criteria were used: never; moderate, if one or two drinks daily; excessive, if three drinks daily; alcoholism; and abstinence, if at least a year had passed since the last drink. Evaluation of vascular risk was performed considering the three most used scores: Framingham risk score (FRS), atherosclerotic cardiovascular disease (ASCVD) - AHA/ACC, ${ }^{11}$ and systematic coronary risk evaluation (SCORE)-ESC. ${ }^{7}$

Results were summarized as mean, median and standard deviation or count and percentage, for characterization of the study population. Normality distribution of data was assessed by the usual methodology used for validation (i.e., Kolmogorov-Smirnov test and Shapiro-Wilk test). For quantitative comparison of two independent groups, we used the t-test for independent samples or the Mann-Whitney nonparametric test, depending on the assumptions' validation by the statistical test. Spearman's correlation coefficient (SCC) was used to assess the relationship between two quantitative variables, in case the normality assumption was not verified. Regarding the sample distribution by age groups, we used the Kruskal-Wallis (KW) non-parametric test, instead of ANOVA F-test, whenever the distributions within groups presented relevant deviations from normality. The KW test allowed a comparative analysis between three or more independent groups and a quantitative or ordinal variable (as the dependent variable). Bonferroni correction for multiplicity of testing was used to verify age groups contrast $\left[\alpha^{\prime}=0.005\right.$, for $\alpha(0.05) / k$ (10 tests)]. All statistical tests were 2-tailed considering a significance level of $5 \%$. The statistical analysis was conducted using the software IBM $^{\circledR}$ SPSS $^{\circledR}$ Statistics 19.

\section{RESULTS}

\section{Sociodemographic parameters at first consultation}

Most of the patients were women (56.6\%) and Caucasian $(98.6 \%)$. The patients' median age was 46 years. Regarding the educational background, $76.6 \%$ of the patients did not complete the third cycle; of those, $60.5 \%$ completed only the first cycle. Concerning the professional status, $72.5 \%$ of the patients were active and $13.2 \%$ were retired but still working. Among those actively employed patients, $40.5 \%$ had elementary occupations, $17.6 \%$ were skilled industrial, construction or craft workers and $17.4 \%$ were personal, protection or security service workers or sales workers.

\section{Anthropometric and clinical evaluation}

The median weight was $75.3 \mathrm{~kg}$ (range: 7.75 - 125.6 $\mathrm{kg}$ ), while the median body mass index (BMI), calculated in kilogram per square meters, was 28.57 (range, 16.53 $47.63 \mathrm{~kg} / \mathrm{m}^{2}$ ). Amongst the study population, $25.0 \%$ had normal weight and $36.0 \%$ excess weight (BMI, 25 - $29 \mathrm{~kg} /$ $\mathrm{m}^{2}$ ). Moreover, $26.2 \%$ of patients had grade I obesity (BMl $30-34 \mathrm{~kg} / \mathrm{m}^{2}$ ), $9.9 \%$ grade II obesity (BMI $5-39 \mathrm{~kg} / \mathrm{m}^{2}$ ), $2.5 \%$ grade III obesity (BMI $40-44 \mathrm{~kg} / \mathrm{m}^{2}$ ) and $0.4 \%$ morbid obesity (BMI $\geq 45 \mathrm{~kg} / \mathrm{m}^{2}$ ). The abdominal (waist-to-hip) circumference $(A C)$ had a median of $94 \mathrm{~cm}$ (range: $44-138$ $\mathrm{cm}$ ) and the average triceps skinfold (TSF) was $2.51 \pm 1.13$ cm (range: 0.3 - $5.0 \mathrm{~cm}$; median: $2.4 \mathrm{~cm}$ ).

Regarding cardiovascular evaluation, the average systolic blood pressure (SBP) was $145.52 \pm 30.29 \mathrm{mmHg}$ (range: 78 - $300 \mathrm{mmHg}$ ) with a median of $144 \mathrm{mmHg}$. The average diastolic blood pressure (DBP) was $87.91 \mathrm{mmHg}$ (range: 42 - $148 \mathrm{mmHg}$ ) with a median of $90 \mathrm{mmHg}$. In addition, the average heart rate was $88.98 \pm 11.79 \mathrm{bpm}$ (range, $50-170 \mathrm{bpm}$ ) with a median of $90 \mathrm{bpm}$. Overall, $50.6 \%$ of patients had normal cardiac auscultation. ${ }^{12}$

Concerning the lifestyle and patients' habits, $66.0 \%$ had a moderate alcohol consumption, ranging from one $(20.8 \%)$ to two daily drinks (45.2\%), whereas $15.5 \%$ showed an excessive alcohol consumption. Alcoholism was diagnosed in 
$7.0 \%$ of patients and abstinence in $0.4 \%$. Moreover, $71.9 \%$ did not practice regular physical activity, while $75.4 \%$ were non-smokers, $11.6 \%$ were ex-smokers and $13.0 \%$ were smokers.

In terms of the liver morphological evaluation, changes were detected through ultrasound in 509 patients (98.6\%). Briefly, a pattern of hepatic steatosis was found in 435 patients (85.4\%), of which 208 (40.8\%) had associated hepatomegaly. Only $5.6 \%$ of patients presented changes in liver function tests.

\section{Vascular risk calculations}

The 10-year vascular risk was estimated based on the most commonly used vascular risk scores. For the FRS (30 - 74 years), applied to 436 patients, we obtained an average of $36.57 \pm 26.37$ (median: 32.60; range: 1.10 - 99.5), while for ASCVD (40 - 79 years), applied to 338 patients, the average was $24.83 \pm 20.61$ (median: 20.61; range: 0.86 95.69). As for the SCORE low-risk algorithm (45 - 64 years), 202 patients were assessed, obtaining an average of $3.24 \pm$ 3.81 (median: 2.23; range: 0.09 - 27.63).

Thus, both ASCVD and FRS scores revealed a high median value for the estimated vascular risk, at 10 years, whereas the SCORE low-risk algorithm indicated a moderated median value.

\section{Laboratory values}

Laboratory parameters assessed at the first consultation are described in Table 1. Briefly, a relevant increase of $\mathrm{C}$ reactive protein (CRP), fibrinogen, homocysteine and $L p(a)$ were observed. HDLc showed a median value of $29.00 \mathrm{mg} /$ dl (min: $11.00 \mathrm{mg} / \mathrm{dL}$ ), while a median value of $172.00 \mathrm{mg} / \mathrm{dL}$ (max: $299 \mathrm{mg} / \mathrm{dl}$ ) was obtained for LDLc. The average CRP was $1.15 \pm 1.01$ (min-max: $0.5-9.7 \mathrm{mg} / \mathrm{dL}$ ), with a median value of $0.80 \mathrm{mg} / \mathrm{dl}$. An average value of $7.14 \pm 2.80$ (minmax: 2.1 - $16 \mathrm{mg} / \mathrm{dL}$ ) was found for uric acid. Urinary albumin excretion (UAE) showed a median rate of $15.80 \mathrm{mcg} /$ $\mathrm{min} / 24 \mathrm{~h}$ (min-max: 0.5 - $459 \mathrm{mcg} / \mathrm{min} / 24 \mathrm{~h}$ ). Furthermore, the median value for homocysteine was $21.00 \mathrm{mmol} / \mathrm{L}$ ( $\mathrm{min}$ max: $7.0-44.0 \mathrm{mmol} / \mathrm{L}$ ) and the average $\mathrm{Lp}(\mathrm{a})$ was 62.57 \pm 21.64 (min-max: $9.9-110 \mathrm{mg} / \mathrm{dL}$ ), with a median value of $59.00 \mathrm{mg} / \mathrm{dL}$. Overall, normal laboratory values for $\mathrm{Lp}(2)$ (i.e., $<30 \mathrm{mg} / \mathrm{dL}$ ) were found in 25 patients $(4.9 \%)$, while abnormal values were detected in 484 patients (95.1\%).

\section{Association of independent variables and $L p(a)$}

Firstly, we confirmed that our study population did not follow a normal distribution, thus, only non-parametric models were applied. As shown in Table 2, a high positive and significant correlation was detected between the $L p(a)$ and the following variables: IMT $\left(r_{s}=0.575\right)$, LDLC $\left(r_{s}=0.457\right)$ and homocysteine $\left(r_{s}=0.565\right)$, and a negative and weak correlation with HDLc $\left(r_{s}=-0.111\right)$. Moderate, but also significant, correlations were found for CRP $\left(r_{s}=0.354\right)$, abdominal circumference $\left(r_{s}=0.335\right), \mathrm{Hb} \mathrm{A} 1 \mathrm{c}\left(r_{s}=0.307\right)$, and weak correlations for BMI $\left(r_{s}=0.276\right)$ and fast insulin $\left(r_{s}=\right.$ 0.210).

By using the Mann-Whitney test, a significant relationship between $\operatorname{Lp}(\mathrm{a})$ and hepatic steatosis was obtained ( $p$ $<0.001)$. This association corresponded to 435 (85.4\%) patients with hepatic steatosis (median of 65.00, range: 10.0 - 110.0; average: $66.29 \pm 20.11)$ versus $74(14.5 \%)$ patients without hepatic steatosis (median of 39.00 , range: 9.9 - 110.0; average: $40.73 \pm 16.98$ ).

Table 1 - Laboratory parameters, at first consultation

\begin{tabular}{lccccc}
\hline Parameters & $\mathbf{n}$ & Omitted by missing & Mean \pm SD & Median & Range \\
\hline CRP (mg/dL) & 514 & 1 & $1.15 \pm 1.01$ & 0.80 & {$[0.5 ; 9.7]$} \\
HbA1c (\%) & 494 & 22 & $6.47 \pm 1.97$ & 5.90 & {$[3.1 ; 13.6]$} \\
Fructosamine (mmol/L) & 398 & 118 & $263.89 \pm 116.86$ & 201.00 & {$[114 ; 601]$} \\
Fast insulin (micro units/mL) & 481 & 35 & $13.48 \pm 7.62$ & 12.00 & {$[0.8 ; 67]$} \\
Peptide C (ng/mL) & 486 & 30 & $2.57 \pm 1.21$ & 2.20 & {$[0.2 ; 9.4]$} \\
Total cholesterol (mg/dL) & 516 & 0 & $278.69 \pm 61.40$ & 287.00 & {$[98 ; 457]$} \\
HDLc (mg/dL) & 516 & 0 & $29.59 \pm 11.76$ & 29.00 & {$[11 ; 134]$} \\
LDLc (mg/dL) & 516 & 0 & $171.20 \pm 39.01$ & 172.00 & {$[39 ; 299]$} \\
VLDLc (mg/dL) & 516 & 0 & $30.81 \pm 22.33$ & 24.00 & {$[7 ; 294]$} \\
Triglycerides (mg/dL) & 515 & 1 & $186.27 \pm 133.245$ & 147.00 & {$[18 ; 1506]$} \\
Fibrinogen (mg/dL) & 487 & 29 & $369.26 \pm 96.05$ & 369.00 & {$[89 ; 651]$} \\
Homocysteine (mmol/L) & 509 & 7 & $20.82 \pm 5.27$ & 21.00 & {$[7.9 ; 44]$} \\
LP(a) (mg/dL) & 509 & 7 & $62.57 \pm 21.64$ & 59.00 & {$[9.9 ; 110]$} \\
$\quad \leq 30$ (normal) & 25 & 0 & & & {$[2.1 ; 16]$} \\
$\quad>30$ (abnormal) & 484 & 0 & 0 & $4.14 \pm 2.80$ & 7.15 \\
Uric acid (mg/dL) & 516 & 17 & $45.28 \pm 68.33$ & 15.80 & {$[0.5 ; 459]$} \\
Microalbuminuria 24h (mcg/min) & 499 & & &
\end{tabular}

CRP: C-reactive protein; HbA1c: hemoglobin A1c; HDLc: high density lipoprotein cholesterol; LDLc: low density lipoprotein cholesterol; VLDLc: very-low-density lipoprotein cholesterol; LP(a): lipoprotein(a) 
Table 2 - Correlation between $L p(a)$ and the other clinical and biochemical parameters, at first consultation

\begin{tabular}{lcc}
\hline Parameters & sCC & $p$ \\
\hline Lp(a) versus HDLc & $r_{s}=-0.111$ & 0.012 \\
Lp(a) versus LDLc & $r_{s}=0.457$ & $<0.001$ \\
Lp(a) versus Fast insulin & $r_{s}=0.210$ & $<0.001$ \\
Lp(a) versus Hb A1c & $r_{s}=0.307$ & $<0.001$ \\
Lp(a) versus Abdominal circumference (waist-to-hip) & $r_{s}=0.335$ & $<0.001$ \\
Lp(a) versus Height & $r_{s}=0.009$ \\
Lp(a) versus BMI & $r_{s}=0.276$ \\
Lp(a) versus CRP & $r_{s}=0.354<0.842$ \\
Lp(a) versus Homocysteine & $r_{s}=0.565<0.001$ \\
Lp(a) versus IMT & $r_{s}=0.575<0.001$ & $<0.001$ \\
\hline
\end{tabular}

SCC: Spearman correlation coefficient $\left(r_{s}\right)$; LP(a): lipoprotein(a); HDLc: high density lipoprotein cholesterol; LDLc: low density lipoprotein cholesterol; Hb A1c: hemoglobin A1c; BMI: body mass index; CRP: C-reactive protein; IMT: intima-media thickness

The association between $\operatorname{Lp}(\mathrm{a})$ and hepatic steatosis with hepatomegaly was also significant $(p<0.001)$. This analysis compared $208(40.8 \%)$ patients with hepatomegaly (median of 77.90 , range: 10.0 - 110.0; average: 74.90 $\pm 18.81)$ versus $301(59.1 \%)$ patients with steatosis without hepatomegaly (median of 49.00 , range: 9.9 - 105.0; average $54.05 \pm 19.25$ ).

Table 3 describes the results that were significant $(p$ $<0.001$ ), regarding the distribution of $L p(a)$ by age group, with patients older than 50 years, achieving higher median values of $L p(a)$. Multiple comparisons between age groups $\left(\alpha^{\prime}=0.005\right)$ allowed to determine that all groups presented significant differences $(<20$ years versus other age groups, $[p<0.001$ ]; 20 - 34 years vs other age groups [ $p<0.001$ ]; $35-49$ years vs 50 - 64 years [ $p=0.001$ ], $35-49$ years $v s \geq$ 65 years $[p<0.001])$, except for age groups of $50-64$ years $v s \geq 65$ years $(p=0.540)$.

A positive and significant correlation was found between $\mathrm{Lp}(\mathrm{a})$ and the vascular risk scores used in CVD stratification $(p<0.001)$, as shown in Table 4. Correlation between Lp(a) and cardiovascular risks was moderate, and high $L p(a)$ values were associated with high scores of those $\mathrm{CV}$ risks stratification tables (i.e., FRS, ASCVD and SCORE).

\section{DISCUSSION}

The main finding of this study was that average values of $L p(a)$ were increased in patients at high vascular risk and were directly correlated with other CVRF. These data constitute valuable information for clinical evaluation, allowing to infer about the adequate orientations and therapeutic interventions, based on the patients' personal and family history. Moreover, this observation can be employed to all three criteria presented for vascular risk calculation, including the SCORE low-risk algorithm, which is applicable to Portuguese patients.

A significant correlation was observed between $\operatorname{Lp}(a)$ and IMT, BMI, LDLC, homocysteine, CRP and abdominal circumference, as previously described. ${ }^{13,14}$ The negative, weak significant correlation between Lp(a) and HDLc should also be highlighted. In addition, results regarding height were relevant if considering that the Portuguese population presents an average short height and individuals with pyknic morphology are more susceptible to CVD. Furthermore, the pro-inflammatory effect of $L p(a)$ is corroborated by its

Table 3 - Lp(a) distribution by age groups, at first consultation

\begin{tabular}{ccccc}
\hline Age groups & $\mathbf{n}$ & Mean \pm SD & Median & Range \\
\hline$<20$ & 14 & $26.42 \pm 15.87$ & 29.00 & {$[0.0 ; 44.0]$} \\
$20-34$ & 104 & $47.86 \pm 21.43$ & 45.00 & {$[0.0 ; 110.0]$} \\
$35-49$ & 177 & $57.67 \pm 25.98$ & 56.00 & {$[0.0 ; 110.0]$} \\
$50-64$ & 144 & $63.64 \pm 25.67$ & 65.50 & {$[0.0 ; 102.0]$} \\
$\geq 65$ & 77 & $62.50 \pm 26.89$ & 69.00 & {$[0.0 ; 103.0]$} \\
KW (df): value, $p<0.001$ & & & &
\end{tabular}

KW: non-parametric Kruskal-Wallis test; Lp(a): lipoprotein(a)

Table 4 - Correlation between Lp(a) and cardiovascular risk (10 years), at first consultation

\begin{tabular}{lc}
\hline Parameters & Spearman correlation \\
& $\mathbf{r}_{\mathbf{s}}$ \\
\hline Lp(a) versus FRS (30 - 74 years) Initial & $0.458^{*}$ \\
Lp(a) versus ASCVD (40 - 79 years) Initial & $0.414^{*}$ \\
Lp(a) versus SCORE (low-risk algorithm, 45 - 64 years) Initial & $0.391^{*}$ \\
\hline
\end{tabular}

FRS: Framingham risk score; ASCVD: atherosclerotic cardiovascular disease; SCORE: systematic coronary risk evaluation. ${ }^{*} p<0.001$ 
correlation with the CRP. ${ }^{15}$

We also highlight the significant relationship between $L p(a)$ and hepatic steatosis $(p<0.001)$. $L p(a)$ values were considerably higher in patients with steatosis. Further studies are required to better understand the relationship in cases of non-alcoholic fatty liver disease (NAFLD) without secondary causes for steatosis, such as excessive alcohol consumption, virus infection or endocrine disorders.

Although results among adult patients are variable, age has been significantly associated with increased $L p(a){ }^{16}$ Furthermore, besides that $L p(a)$ values increase with age, a significant difference between younger (20 - 39 years) and older ( $>60$ years) subjects has been described. ${ }^{17}$ Therefore, we assessed the effect of age groups on the distribution of $L p(a)$, which showed that $L p(a)$ presented a significant association between age groups, except for the two groups of older patients (50 - 64 years vs $\geq 65$ years; $p=0.540$ ). Thus, an early perception of the vascular risk with an easy and adequate risk stratification in primary prevention should be provided..$^{18}$ This information presupposes an early reflection to restructure the intervention procedure, so that patients' mortality and cardiovascular morbidity are reduced. Also, the positive correlation between $L p(a)$ and vascular risk scores suggest that $L p(a)$ plays a key role in vascular risk estimation. This correlation should be considered when planning or re-evaluating therapy interventions, in terms of primary prevention. ${ }^{18}$

$L p(a)$ presents some unique features that enable it to enrich the atherosclerotic plaques of cholesterol. Additionally, this lipoprotein has been shown to increase smooth muscle cell migration and proliferation, chemotactic activity, endothelial adhesion molecule expression, foam cell formation and lipid-induced atherogenesis. $L p(a)$ particles accumulate in human atherosclerotic lesions in the same way as LDLc, but probably more easily, due to their greater affinity to the arterial wall than LDLc. For this reason, increased values of $L p(a)$ represent a CVRF and should be treated. ${ }^{19,20}$

Similarly to CVD, treatment of NAFLD is focused on reducing CVRF and resistance to insulin. Since well-established therapeutic options are still lacking, lifestyle modifications and treatment of individual risk factors are recommended. ${ }^{21,22}$ Neverthless, albeit the known benefits of diet, followed by physical activity and adequate control of modifiable risk factors, it hasn't been demonstrated that those interventions have an impact on Lp(a) levels. ${ }^{23}$ Considering the present results for the Portuguese patients, we can infer that, although the Mediterranean diet is an essential part of primary prevention, ${ }^{24,25}$ it should not be overrated compared to other CVRF that have stronger associations with CVD and related consequences. ${ }^{26,27}$ Therefore, the increased fo- cus on the Mediterranean diet may have contributed to the postponing of more incisive interventions and therapeutic orientations that, if initiated early, could be decisive in reducing the burden of cardiovascular disease. ${ }^{28,29}$

Overall, $L p(a)$ is associated with conventional CVRF, including high levels of LDLC, and were found to be increased in patients with hepatic steatosis and those with high vascular risk. As such $L p(a)$ should be valued as a biomarker for an early initiation of therapy and intensive orientations for primary prevention of CVD. . $12,20,23,30^{2}$

Finally, this study presents some limitations inherent to its design and observational nature. For instance, the interpretation of our results should account for possible withinsubject variation and control variables (e.g., BMI, blood pressure and laboratory parameters, such as CRP or $\mathrm{Hb}$ Ac1), as well as omitted individuals (missing data), over the study period. Despite these limitations, this study provides us with unique data about the $L p(a)$ profile in Portuguese patients at high risk of vascular disease, with implications in current clinical practice.

\section{CONCLUSION}

In conclusion, $L p(a)$ is a strong indicator of vascular risk, directly correlated with all markers of cardiovascular risk and with non-alcoholic hepatic steatosis. Due to its high availability and low cost, $L p(a)$ should become part of routine evaluation of at-risk patients in the Portugal.

\section{ACKNOWLEDGMENTS}

A grateful acknowledgement is due to Antonio Coca for helpful comments on this work.

\section{PROTECTION OF HUMANS AND ANIMALS}

The authors declare that the procedures were followed according to the regulations established by the Clinical Research and Ethics Committee and to the Helsinki Declaration of the World Medical Association.

\section{DATA CONFIDENTIALITY}

The authors declare having followed the protocols in use at their working center regarding patients' data publication.

\section{CONFLICTS OF INTEREST}

All authors report no conflict of interest.

\section{FUNDING SOURCES}

This research received no specific grant from any funding agency in the public, commercial, or not-for-profit sectors.

rich apolipoprotein-B-containing lipoproteins in the pathogenesis of atherosclerosis: a triumph of simplicity. Curr Opin Lipidol. 2016.27:47383.

3. Gu Q, Paulose-Ram R, Burt VL, Kit BK. Prescription cholesterol-lowering

\section{REFERENCES}

1. Sidney S, Quesenberry CP, Jaffe MG, Sorel M, Nguyen-Huynh MN, Kushi LH, et alS. Recent trends in cardiovascular mortality in the United States and public health goals. JAMA Cardiol. 2016;1:594-9.

2. Boren J, Williams KJ. The central role of arterial retention of cholesterol- 
medication use in adults aged 40 and over: United States, 2003-2012. NCHS Data Brief, 2014:1-8.

4. Tani M, Horvath KV, Lamarche B, Couture P, Burnett JR, Schaefer EJ, et al. High-density lipoprotein subpopulation profiles in lipoprotein lipase and hepatic lipase deficiency. Atherosclerosis. 2016;253:7-14.

5. Feinberg MW. No small task: therapeutic targeting of $L p(a)$ for cardiovascular disease. Lancet. 2016;388:2211-2.

6. Norgren L, Hiatt WR, Dormandy JA, Nehler MR, Harris KA, Fowkes FG. Inter-Society Consensus for the Management of Peripheral Arterial Disease (TASC II). J Vasc Surg. 2007:45:S5-67.

7. Catapano AL, Graham I, De Backer G, Wiklund O, Chapman JM, Drexel H, et al. 2016 ESC/EAS Guidelines for the Management of Dyslipidaemias. Eur Heart J. 2016.37:2999-3058.

8. Hojo $\mathrm{Y}$, Kumakura $\mathrm{H}$, Kanai $\mathrm{H}$, Iwasaki $\mathrm{T}$, Ichikawa $\mathrm{S}$, Kurabayashi M. Lipoprotein(a) is a risk factor for aortic and mitral valvular stenosis in peripheral arterial disease. Eur Heart $\mathrm{J}$ Cardiovasc Imaging. 2016;17:492-7.

9. Anuurad E, Boffa MB, Koschinsky ML, Berglund L. Lipoprotein(a): a unique risk factor for cardiovascular disease. Clin Lab Med. 2006;26:75172.

10. Townsend N, Wilson L, Bhatnagar P, Wickramasinghe K, Rayner M, Nichols M. Cardiovascular disease in Europe: epidemiological update 2016. Eur Heart J. 2016;37:3232-45.

11. Goff DC, Lloyd-Jones DM, Bennett G, Coady S, D'Agostino RB, Gibbons $\mathrm{R}$, et al. 2013 ACC/AHA guideline on the assessment of cardiovascular risk: a report of the American College of Cardiology/American Heart Association Task Force on Practice Guidelines. Circulation. 2014;129: S49-S73.

12. Mancia G, Fagard R, Narkiewicz K, Redón J, Zanchetti A, Böhm M, et al. 2013 ESH/ESC guidelines for the management of arterial hypertension: the Task Force for the Management of Arterial Hypertension of the European Society of Hypertension (ESH) and of the European Society of Cardiology (ESC). Eur Heart J. 2013;34:2159-219.

13. El-Gendi SS, Bakeet MY, El-Hamed EA, Ibrahim FK, Ahmed R. The value of lipoprotein (a), homocysteine, and Doppler of carotid and femoral arteries in assessment of atherosclerosis in asymptomatic cardiovascular risk patients. J Cardiol. 2008;52: 202-11.

14. Lloyd-Jones DM, Goff D, Stone NJ. Statins, risk assessment, and the new American prevention guidelines. Lancet. 2014;383: 600-2.

15. Orso E, Schmitz G. Lipoprotein(a) and its role in inflammation, atherosclerosis and malignancies. Clin Res Cardiol Suppl. 2017;12:S317.

16. Akita $H$, Matsubara $M$, Shibuya $H$, Fuda $H$, Chiba $H$. Effect of ageing on plasma lipoprotein(a) levels. Ann Clin Biochem. 2002;39:237-4.

17. Enkhmaa B, Anuurad E, Berglund L. Lipoprotein (a): impact by ethnicity and environmental and medical conditions. J Lipid Res. 2016;57:111125.

18. Koschinsky ML, Boffa MB. Lipoprotein(a): an important cardiovascular risk factor and a clinical conundrum. Endocrinol Metab Clin North Am. 2014;43: 949-62.

19. Bucci M, Tana C, Giamberardino MA, Cipollone F. Lp(a) and cardiovascular risk: Investigating the hidden side of the moon. Nutr Metab Cardiovasc Dis. 2016;26:980-6.

20. Eckardstein AV. Will you, nill you, I will treat you: the taming of lipoprotein(a). Eur Heart J. 2017;38:1570-2

21. Byrne CD, Targher G. NAFLD: a multisystem disease. J Hepatology. 2015;62:S47-64

22. Patil R, Sood GK. Non-alcoholic fatty liver disease and cardiovascular risk. World J Gastrointest Pathophysiol. 2017;8:51-8.

23. Eckardstein AV. Lipoprotein(a). Eur Heart J. 2017;38:1530-41.

24. Estruch R, Salas-Salvado J. Towards an even healthier Mediterranean diet. Nutr Metab Cardiovasc Dis. 2013;23:1163-6.

25. Appel LJ, Van Horn L. Did the PREDIMED trial test a Mediterranean diet? N Engl J Med. 2013;368:1353-4.

26. Boffa MB, Koschinsky ML. Lipoprotein (a): truly a direct prothrombotic factor in cardiovascular disease? J Lipid Res. 2016;57:745-57.

27. Koschinsky M, Boffa M. Lipoprotein(a) as a therapeutic target in cardiovascular disease. Expert Opin Ther Targets. 2014;18: 747-57.

28. Yusuf S, Bosch J, Dagenais G, Zhu J, Xavier D, Liu L, et al. Cholesterol lowering in intermediate-risk persons without cardiovascular disease. $\mathrm{N}$ Engl J Med. 2016;374: 2021-31.

29. Minder CM, Blumenthal RS, Blaha MJ. Statins for primary prevention of cardiovascular disease: the benefits outweigh the risks. Curr Opin Cardiol. 2013;28: 554-60.

30. Gencer B, Kronenberg F, Stroes ES, Mach F. Lipoprotein(a): the revenant. Eur Heart J. 2017;38:1553-60. 